\title{
Are Spanish Health Services Appropriate To The Needs Of People With Disabilities?
}

María-Leticia Meseguer-Santamaría, University of Castilla-La Mancha, Spain José Mondéjar-Jiménez, Ph.D., University of Castilla-La Mancha, Spain Manuel Vargas-Vargas, Ph.D., University of Castilla-La Mancha, Spain

\begin{abstract}
In recent decades, social policies have advanced greatly in developed countries, especially with regard to disabilities. This has led to greater resources for these social policies, especially those related to health care. However, people with disabilities have different needs, which are not always reflected in health service care. So, using data of the 2006 Spanish National Health Survey (ENSE 2006), this study focuses on this group of people and analyses the main causes for which they do not receive the health care required. It also examines their healthy behaviour habits, highlighting possible differences with the entire population. This information should be considered when providing health and social care services to people with disabilities.
\end{abstract}

Keywords: Persons with Disabilities, Health Care Services.

\section{INTRODUCTION}

$\mathrm{n}$ recent decades, health needs which are more related to the assistance and care of citizens than to classical medicine have arisen. This has led to a new type of health care and social work, integrating medical-hospital care with social service assistance (Jiménez and Zabarte, 2008).

People with dependency or with disabilities make up one of the groups which have most benefitted from this integrated service. However, the process is not complete since greater coordination is needed between the social and health areas as is a greater adaptation to the specific needs of each group. In Spain, some empirical studies (Abellán and Puja, 2004; Bayot, 2006; Jiménez y Huete, 2003; Muus, 2009; Pascual and Cantarero, 2007) look at the social and health care situation of people with disabilities or dependency. Studies focussing on the situation of women with disabilities also exist (Mondéjar, Vargas, Meseguer and Mondéjar, 2009; Mondéjar, Vargas, Mondéjar and Bayot, 2009) which address the specific needs of this particular group.

Within this framework, our study examines the principal reasons why people with disabilities do not receive the required care from the health services and the differences which exist between this group and the Spanish population as a whole regarding preventive medicine and health related habits. The source of quantitative information is the 2006 Spanish National Health Survey (ENSE 2006) which provides official data on the prevalence of people with disabilities among the population and the use of the health and social care system.

\section{METHODOLOGY}

This research work analyses the number of people with disabilities in the adult population in Spain (16 years and over) based on the ENSE 2006, carried out by the Health Training Institute of the Ministry of Health and Consumer Affairs in collaboration with the National Institute of Statistics.

In this survey the study of disability is based on the answers provided in section "N-Limitations for the carrying out of activities of daily living", specifically question number 137: "Over at least the last six months, to what degree has a problem of health limited you in the carrying out of habitual activities?" The individuals who replied "Seriously limited" or "Limited but not seriously" were classified as people with some degree of disability, 
while those who replied "Not limited" were classified as being without disability. This choice coincides with the one used in the latest survey on disability conducted in Spain, Survey on Disability, Personal Autonomy and Dependency Situations (EDAD 2008) and is similar to the one used in the International Classification of Functioning, Disability and Health (World Health Organization 2001), which also alludes to difficulties in carrying out activities of daily living, within the social model of disability (Jiménez, González and Martín, 2002; Malo, 2007). In this article we will make a distinction between three situations: people with severe disabilities, with moderate disabilities and those without disabilities. On some occasions, when the analysis justifies it, the first two categories will be combined, without any distinction.

Although the EDAD 2008 shows quantitative information on social and health assistance for people with disabilities, it neither includes generic aspects on lifestyles nor does it allow for the comparison of this group with the general population. These aspects, however, were included in the 2006 Spanish National Health Survey, which, due to its continuing nature can also address comparative or time series studies.

\section{EMPIRICAL FINDINGS}

In Spain $23.2 \%$ of the population has a disability. This makes a total of $8,681,740$ people, of whom $1,717,322(4.6 \%)$ consider themselves to be severely limited. By gender there is a greater percentage of women in both categories, as can be seen in Figure 1.

Figure 1: Prevalence of people with disabilities by gender

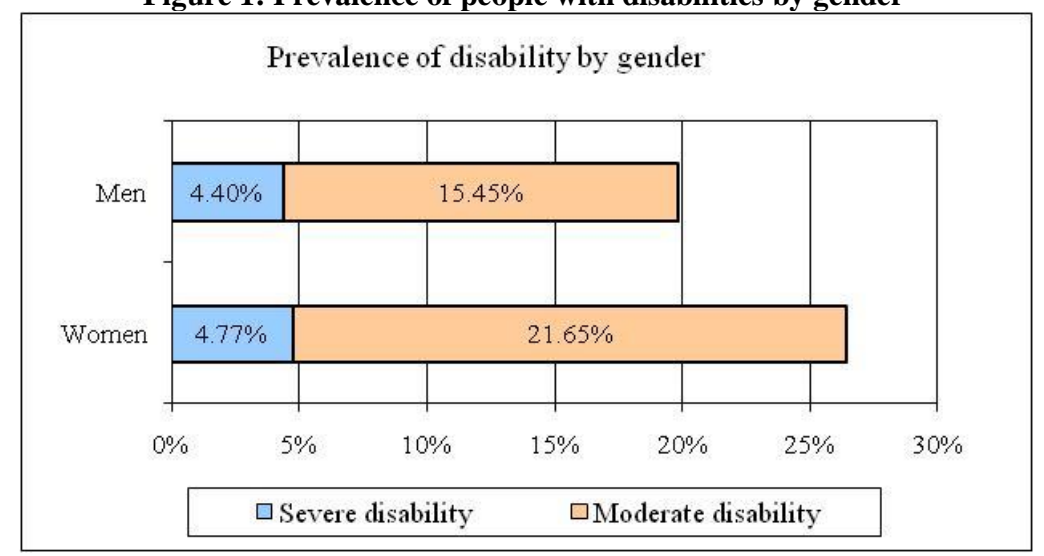

Source: Drawn up according to data from the 2006 Spanish National Health Survey, Madrid, 2007.

Figure 2: Prevalence of disability by age

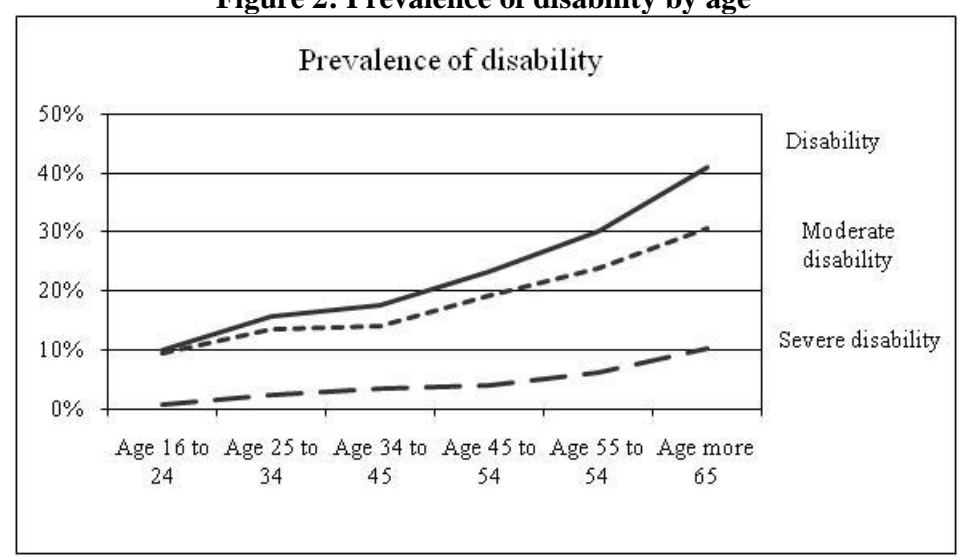

Source: Drawn up according to data from the 2006 Spanish National Health Survey, Madrid, 2007. 
A positive correlation exists between age and the prevalence of disability. The $10 \%$ of people between the ages of 16 and 24 with disabilities, either severe or moderate, may be compared with the almost $41 \%$ of people over the age of 65. The graph in Figure 2 represents the prevalence of moderate and severe disability and disability in general. There are two inflection points, at approximately age 40 and 60, after which the slope increases, due to disability intensifying with age.

If we analyse the need for medical assistance which was not received, there exist notable major differences by gender or by disability or non-disability. In comparison to the $11.6 \%$ of women with a severe disability who declare that on at least one occasion they have not received medical assistance when it was needed, the figure for men without disabilities is only $2.1 \%$.

Figure 3: Medical assistance needed but not received

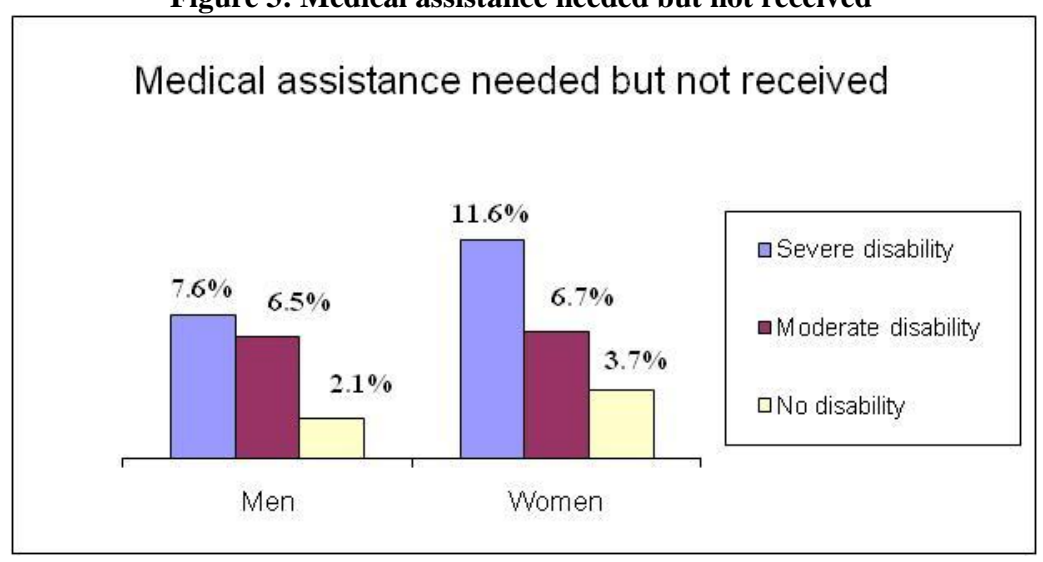

Source: Drawn up according to data from the 2006 Spanish National Health Survey, Madrid, 2007.

The most common cause, in around a third of the cases, is "There was a long wait." There is a higher percentage of women with disability, but the difference compared with other groups is not significant. By gender, women had more problems regarding the first cause in the list, "Could not get an appointment", however men had more problems with work related reasons (second cause). The monetary cause It was too expensive/had no money, is a major cause among men with a severe disability (4.6\%), while for women in the same segment it was not a cause at all.

Table 1: Main causes of lack of assistance

\begin{tabular}{|l|c|c|c|c|c|c|}
\cline { 2 - 6 } \multicolumn{1}{c|}{} & \multicolumn{2}{c|}{ Severe disability } & \multicolumn{2}{c|}{ Moderate disability } & \multicolumn{2}{c|}{ No disability } \\
\cline { 2 - 7 } \multicolumn{1}{c|}{ Couldn't get an appointment } & Men & Women & Men & Women & Men & Women \\
\hline Couldn't leave work & $8.40 \%$ & $14.40 \%$ & $16.10 \%$ & $18.60 \%$ & $14.30 \%$ & $22.90 \%$ \\
\hline It was too expensive / had no money & $6.00 \%$ & $0.00 \%$ & $6.30 \%$ & $5.20 \%$ & $15.50 \%$ & $7.20 \%$ \\
\hline Had no transport & $4.60 \%$ & $0.00 \%$ & $1.30 \%$ & $1.00 \%$ & $2.90 \%$ & $2.60 \%$ \\
\hline Was too nervous & $3.20 \%$ & $1.90 \%$ & $4.20 \%$ & $3.10 \%$ & $2.60 \%$ & $1.50 \%$ \\
\hline Not covered by insurance & $3.60 \%$ & $4.10 \%$ & $3.50 \%$ & $2.30 \%$ & $1.70 \%$ & $2.00 \%$ \\
\hline No insurance & $5.00 \%$ & $3.60 \%$ & $5.20 \%$ & $0.10 \%$ & $0.70 \%$ & $1.60 \%$ \\
\hline The wait was too long & $0.00 \%$ & $0.00 \%$ & $0.20 \%$ & $1.80 \%$ & $0.20 \%$ & $1.40 \%$ \\
\hline Impeded by family obligations & $25.60 \%$ & $31.00 \%$ & $29.30 \%$ & $34.70 \%$ & $34.40 \%$ & $27.40 \%$ \\
\hline Other causes & $0.00 \%$ & $5.20 \%$ & $3.40 \%$ & $1.70 \%$ & $0.30 \%$ & $3.40 \%$ \\
\hline St & $43.50 \%$ & $39.80 \%$ & $30.40 \%$ & $31.40 \%$ & $27.50 \%$ & $29.90 \%$ \\
\hline
\end{tabular}

Source: Drawn up according to data from the 2006 Spanish National Health Survey, Madrid, 2007. 
Transport was a greater problem for people with disabilities, especially for those with a moderate disability. It was also a greater problem for men than for women as can be seen in Table 1 . There was a significantly higher percentage of women who did not receive medical assistance due to family obligations, except in the case of men with a moderate disability. In the case of men without disabilities or those with a severe disability the percentage was close to zero.

By disability groups and for the female segment, we may observe that in women with a severe disability, in $55 \%$ of the cases the lack of medical assistance is due to four causes: "the wait was too long", "couldn't get an appointment", "impeded by family obligations" and "was too nervous". In the case of women with a moderate disability, around $60 \%$ attribute the lack of assistance to the following four causes: "the wait was too long", "couldn't get an appointment", "couldn't leave work" and "had no transport".

If we examine the use of preventive medicine, differences between people with and without disabilities do exist but there are none between men and women. Table 2 shows the percentages within each group of disability and sex for people who have made use of the corresponding measure in the last 12 months.

Table 2: Preventive health measures in the last 12 months

\begin{tabular}{|l|c|c|c|c|c|c|}
\multicolumn{1}{c|}{} & \multicolumn{2}{c|}{ Severe disability } & \multicolumn{2}{c|}{ Moderate disability } & \multicolumn{2}{c|}{ No disability } \\
\cline { 2 - 7 } \multicolumn{1}{c|}{} & Men & Women & Men & Women & Men & Women \\
\hline Visit to dentist, stomatologist or dental hygienist & $28.90 \%$ & $29.10 \%$ & $33.60 \%$ & $40.10 \%$ & $35.20 \%$ & $41.70 \%$ \\
\hline Taking blood pressure & $90.90 \%$ & $89.90 \%$ & $82.70 \%$ & $85.50 \%$ & $73.70 \%$ & $71.40 \%$ \\
\hline Measuring cholesterol levels & $85.00 \%$ & $82.60 \%$ & $80.30 \%$ & $81.40 \%$ & $70.40 \%$ & $69.20 \%$ \\
\hline Flu vaccine & $44.50 \%$ & $46.70 \%$ & $35.60 \%$ & $36.10 \%$ & $18.30 \%$ & $17.80 \%$ \\
\hline
\end{tabular}

Source: Drawn up according to data from the 2006 Spanish National Health Survey, Madrid, 2007.

People with disabilities are those most interested in preventive medicine with no appreciable difference between sexes. In the case of dental hygiene, an important component of the general state of health, women without disabilities form the group with the highest percentage. Mouth infections or loss of teeth can cause serious, chronic damage to the stomach among other complaints.

As preventive measures, testing blood pressure or cholesterol levels can give warning about the malfunction of certain organs, alerting to the need to act quickly and immediately so as to avoid worsening health. In these cases it is women with severe or moderate disabilities who most usually test for these indicators; $89.9 \%$ and $85.5 \%$ respectively have their blood pressure taken and 82.6 and $81.4 \%$ have their cholesterol levels checked. This is over $10 \%$ more than in the case of women without disabilities.

Other indicator to be taken into account when studying the use of health services are those related to habits of health behaviour, which directly influence the state of health. First individuals were examined for smoking habits, be it cigarette, cigars or pipe smoking. Only half as many women as men with disabilities smoked while the difference between sexes was noticeably reduced in the case of people without disabilities. People with a moderate disability of both sexes were those who most smoked.

Table 3: Health-related behaviour

\begin{tabular}{|c|c|c|c|c|c|c|}
\hline & \multicolumn{2}{|c|}{ Severe disability } & \multicolumn{2}{|c|}{ Moderate disability } & \multicolumn{2}{|c|}{ No disability } \\
\hline & Men & Women & Men & Men & Women & Men \\
\hline Smokes cigarettes, cigars or a pipe & $26.90 \%$ & $13.70 \%$ & $49.40 \%$ & $24.30 \%$ & $34.90 \%$ & $24.30 \%$ \\
\hline Drinks wine or beer & $49.75 \%$ & $34.57 \%$ & $53.89 \%$ & $33.47 \%$ & $51.20 \%$ & $33.89 \%$ \\
\hline Drinks brandy, whisky or mixed drinks & $7.50 \%$ & $2.17 \%$ & $12.48 \%$ & $3.77 \%$ & $16.76 \%$ & $6.65 \%$ \\
\hline Sleeps long enough to permit rest & $70.30 \%$ & $52.80 \%$ & $75.10 \%$ & $61.90 \%$ & $84.80 \%$ & $77.60 \%$ \\
\hline Does some sort of physical activity in his/her free time & $43.63 \%$ & $32.15 \%$ & $61.61 \%$ & $53.50 \%$ & $64.40 \%$ & $60.48 \%$ \\
\hline Overweight & $39.20 \%$ & $25.70 \%$ & $41.60 \%$ & $28.30 \%$ & $43.80 \%$ & $26.20 \%$ \\
\hline Obesity & $20.70 \%$ & $23.10 \%$ & $20.30 \%$ & $21.10 \%$ & $16.40 \%$ & $13.30 \%$ \\
\hline On some sort of diet to lose weight & $7.30 \%$ & $13.10 \%$ & $14.80 \%$ & $21.90 \%$ & $22.10 \%$ & $44.70 \%$ \\
\hline
\end{tabular}

Source: Drawn up according to data from the 2006 Spanish National Health Survey, Madrid, 2007. 
With regard to the consumption of alcohol, daily and weekly frequency was considered and a distinction was made between drinks with lower alcohol content (wine and beer) and those with a higher alcohol content (whisky, brandy and other mixed drinks). In the first case, about a third of the women are habitual consumers of alcohol, compared with half of the men, regardless of whether they have a disability or not. However, in the second case, the table shows differences depending on the degree of disability. As the degree of disability decreases, the rate of habitual consumers increases significantly. As for differences by gender, men practically triple the percentage of women in all groups.

A study was also made of whether the daily rest of these individuals was sufficient. The highest percentage of those who did not get all the sleep they needed was the $47.2 \%$ of women with disabilities while the smallest percentage was the $15.6 \%$ of men without disabilities.

The respondents were also asked about the physical exercise they did in their free time, with significant differences being found both in the comparison between sexes and in the comparison between degrees of disability. $32.15 \%$ of women with a severe disability do some physical exercise in comparison with $60.48 \%$ of those without disability. In all the categories of disability the percentage of men is higher than that of women although the difference decreases according to the degree of disability.

Finally overweight and obesity were analysed and respondents were also asked if they were on a diet to lose weight. The body mass index (BMI) was used to classify people according to weight. Those overweight had a BMI between 25 and 29.9 and the obese had an index of over 30. Results showed that while in the category of overweight there were no significant differences between the sexes, in the case of obesity, the percentage of men was over $10 \%$ greater in all disability groups. It is also worth noting the difference between the $23.1 \%$ of women with a severe disability who are obese and the $13.3 \%$ of those who have no disability. When asked if they were on a weight loss diet, the percentage of women was higher, especially among women without disability, reaching $45 \%$.

\section{CONCLUSIONS}

People with disabilities account for almost a quarter of the entire population. Of these, $4 \%$ have a severe disability and $19 \%$ have a moderate disability. There is a greater prevalence among women and a positive correlation with age. Despite these people's greater need for health and social care, health services must continue adapting to their demands and characteristics, which are different from those of the general population. For that reason this study focuses on identifying the most frequent causes of lack of health care, preventive health and healthy behaviour habits among people with disabilities in Spain.

The lack of medical assistance is most frequent in the group of women with a severe disability. The main causes are not being able to get an appointment and having to wait too long. The female segment has higher percentages also with regard to family obligations, except in the case of those women with a severe disability. However men have more problems with getting time off work. In the case of It was too expensive/had no money, the percentage of men with a severe disability was 4.6 while curiously the figure was null in the same group of women with a disability. Also the lack of transport, feeling too nervous or lacks of insurance cover were the most frequent causes among people with disabilities.

People with disability have a greater awareness of preventive medicine, as shown by the data relating to measuring blood pressure and cholesterol levels or the flu vaccine. With regard to oral health people without disabilities have higher percentages but the differences are smaller than in the other. The only significant differences by gender were registered in this last indicator, where it was women, with or without disabilities, who most visited the dentist, stomatologist or dental hygienist.

With reference to behavioural habits, women smoke, drink, sleep well and are suffer from overweight less than men. The percentage decreases in both sexes as the degree of disability increases, except in the case of overweight. People with disabilities do less physical exercise and follow less weight loss diets. Women are the less active and those who most diet. 


\section{ACKNOWLEDGEMENTS} 2009-2011).

This study has been developed within the Research Project whose reference is: PII1I09-0109-6105 (JCCM,

\section{AUTHOR INFORMATION}

María-Leticia Meseguer-Santamaría: MBA in Economics Degree in Business Administration by University of Castilla-La Mancha. Assistant Professor in Statistics at Statistics Department. Faculty of Economics and Business Administration of Albacete. University of Castilla-La Mancha (Spain). E-mail: MLeticia.Meseguer@uclm.es. Research Interest: disability, women studies, educational and tourism.

José Mondéjar-Jiménez: European $\mathrm{PhD}$ in Economics and Degree in Business Administration by University of Castilla-La Mancha. Associate Professor at Statistics Department. Faculty of Social Sciences of Cuenca. University of Castilla-La Mancha (Spain). E-mail: Jose.Mondejar@uclm.es.

Research Interest: disability, regional analysis, educational and tourism.

Manuel Vargas-Vargas: PhD in Economics by University of Castilla-La Mancha and Degree in Mathematics by University of Granada. Associate Professor in Statistics at Statistics Department. Faculty of Economics and Business Administration of Albacete, University of Castilla-La Mancha (Spain). E-mail: Manuel.Vargas@uclm.es. Research Interest: disability, regional analysis, educational and tourism.

\section{REFERENCES}

1. Abellán, A. \& Puja, M. D. (2004). Una estimación de la dependencia. Revista Multidisciplinar de gerontología, 14(5), 301-303.

2. Bayot, A. (2006). Estudio cualitativo de la situación de la mujer con discapacidad en Castilla-La Mancha. Toledo. COCEMFE.

3. Instituto Nacional de Estadística (2009). Encuesta sobre Discapacidad, Autonomía Personal y Situaciones de Dependencia de 2008. Metodología. Madrid.

4. Jiménez, A. \& Huete, A. (2003). La discapacidad en España: Datos estadísticos. Aproximación desde la Encuesta sobre Discapacidades, Deficiencias y Estado de Salud de 1999, Doc. 62/2003. Madrid. Real Patronato sobre Discapacidad.

5. Jiménez, A. \& Zabarte, M. E. (2008). La regulación de la prestación sociosanitaria. Propuesta del CERMI. Colección CERMI.es, 33. Madrid: Ediciones Cinca.

6. Jiménez, M. T.; González, P. \& Martín, J. M. (2002). La clasificación internacional del funcionamiento de la discapacidad y de la salud (CIF) 2001. Revista Española de Salud Pública, 76(4), 271-279.

7. Malo, M. A. (2007): La definición de la discapacidad en la investigación económica: Una reflexión necesaria sobre qué características debería cumplir, Estudios de Economía Aplicada, 25(2), 407-428.

8. Ministerio de Sanidad y Consumo. Instituto de Información Sanitaria del SNS. Encuesta Nacional de Salud de España 2006. [Internet] Madrid, 2007. Available on: http://www.msc.es/estadEstudios/estadisticas/encuestasNacional/encuesta2006.htm.

9. $\quad$ Mondéjar, J., Vargas M., Meseguer, M. L. \& Mondéjar, J. A. (2009). Impact of social factors on labour discrimination of disabled women, Research in Developmental Disabilities, 30, 1115-1123.

10. Mondéjar, J, Vargas, M., Mondéjar, J. A. \& Bayot, A. (2009). An approach to the socio-labour situation of disabled women in rural communities in a Spanish region, Disability \& Rehabilitation, 31, 1328-1337.

11. Muus, K. (2009) Health-Related Attributes of North Dakota Adults with Disabilities: Analysis of 2001 2007. BRFSS Data,

12. Organización Mundial de la Salud (2001). Clasificación Internacional del Funcionamiento, de la Discapacidad y de la Salud: CIF. Madrid: Instituto de Migraciones y Asuntos Sociales (IMSERSO). http://www.ilo.org/public/spanish/employment/skills/disability/draftcod.htm

13. Pascual, M. y Cantarero, D. (2007). Características socio-económicas de las personas con discapacidad en España: Un análisis empírico, Estudios de Economía Aplicada, vol. 25(3), 843-866. 